\title{
Escritura y realidad en tres cuentos de Leonardo Padura: estructura metonímica de la prosa como procedimiento de desjerarquización
} Writing and reality in three stories by Leonardo Padura: metonymic structure of
prose as a process of de-hierarchization

\author{
Marcos Mondoñedo \\ Universidad Nacional Mayor de San Marcos, Lima, Perú \\ Contacto:mmondonedom@unmsm.edu.pe \\ https://orcid.org/0000-0002-2162-1274
}

\begin{abstract}
Resumen
Este trabajo desarrolla un análisis de los procedimientos retóricos propios de la prosa de algunos cuentos de Leonardo Padura: "Según pasan los años", "El cazador", "La puerta de Alcalá". En ellos se configuraría una suerte de "aplanamiento" de los diversos elementos de la representación narrativa. Este procedimiento puede describirse como una continuidad metonímica o como una "textualización" de diversos planos de inmanencia semiótica, lo cual traería como consecuencia una especial verosimilitud narrativa: la realidad ficcional y la realidad histórica se continúan disolviendo sus límites y sin aparente cambio de nivel de pertinencia. De este modo, se extienden los dominios de la ficción al campo de las formas de vida y se proyectan dichas formas a la inmanencia textual.
\end{abstract}

Palabras clave: Leonardo Padura, metonimia, cuentos, escritura narrativa, realidad

\begin{abstract}
:
This work develops an analysis of the rhetorical procedures of the prose of some stories by Leonardo Padura: "Según pasan los años", "El cazador", "La puerta de Alcalá". In them in a vaguely way a "flattening" of the several elements of narrative representation would be configured. This procedure can be described as a metonymic continuity or as a "textualization" of various planes of semiotic immanence, which would result in a special narrative verisimilitude: the fictional and historical reality keeps dissolving their limits with any apparent change in a pertinent level. In this way, the domains of fiction are extended to the field of life forms and these forms are projected to textual significance.
\end{abstract}

Keywords: Leonardo Padura, Metonymy, Stories, Narrative writing, Reality

Recibido: $17.11 .17 \quad$ Aceptado: 04.04.18 
Queremos iniciar este breve ensayo con una muy elemental constatación: la práctica de la escritura tiene como resultado el soporte de una distancia, aquella que permite la observación, el análisis, el cuestionamiento. Dicho de otro modo, lo escrito no solo contiene lo que se quiere representar, sino que también otorga - $\mathrm{y}$, en primer lugar, se la otorga al escritor - una posición desde la cual organizar, con los mecanismos de la significación y de la lógica, los hechos cuyo devenir siempre nos sorprenden por su multiplicidad y su contingencia.

La escritura narrativa, más concretamente y por su naturaleza, se orienta desde esta posición distanciada y organizadora hacia los sucesos de la realidad y a su relación con las nociones que, desde algún sentido común, quieren asirla. Podría objetarse de inmediato que ya el lenguaje, sin la escritura como práctica, tiene esa doble orientación: hacia el decir algo, una inmanencia, y hacia el referirse al mundo, una trascendencia. Pero lo que decimos es que la escritura, o más precisamente su producto, lo escrito, añade el soporte de una distancia y, por eso mismo, una objetivación desde la cual es factible la producción de un conocimiento que el habla en sí misma impide ${ }^{1}$.

No obstante, esta objetivación que la escritura produce no es, necesariamente, verosímil. De hecho, lo que los historiadores, los sociólogos, pero también los físicos y otros científicos dedicados a observar el universo, lo que todos ellos nos muestran en sus escritos como resultado de sus análisis de la realidad, nos sorprende. Solo son creíbles por la institucionalidad universitaria que esa escritura requiere para la afirmación de sus novedades. Incluso así, lo que algunos desean con ese conocimiento es acallarlo o desacreditarlo, porque muchas veces cuestiona un modo de vida o una concepción del mundo que otorga un confort desigual.

En consecuencia, la escritura que desee obtener verosimilitud por medios no institucionales y académicos deberá confiar en ciertas operaciones que son exclusivas de la materia con la que la escritura trabaja, la materia del significante. Arribamos, así, a otra constatación: la distancia que la escritura permite para 
producir conocimiento sobre la realidad requiere, para ser convincente sin el aval institucional, de una aproximación hacia la realidad que se realiza con procedimientos que no son de ella, sino de los significantes.

En la escritura de los cuentos de Leonardo Padura podemos percibir con intensidad esta tensión, una que le permite en la escritura de las novelas indagaciones más profundas y convincentes ${ }^{2}$. Y esta tensión es, precisamente, aquella que se establece entre la distancia cognoscitiva sobre la realidad histórica de su país y la aproximación verosímil respecto de la misma. Lo que proponemos verificar es, concretamente, que esta última vertiente, la de la cercanía aparente, se realiza a través de un procedimiento retórico preciso, la configuración metonímica de la realidad.

Como se sabe, la metonimia es un tropo cuya operación consiste en una transferencia semántica que, a diferencia de la metáfora, no se realiza paradigmáticamente, es decir, a través de la conexión de dos campos semánticos distantes; la metonimia opera, antes bien, por contigüidad, de modo sintagmático (cfr. Marchese \& Forradelas, 1988, p. 262). Los varios tipos de este recurso alistados en los diccionarios se diferencian por la relación que establecen: efecto y causa, materia y cosa, continente y contenido, abstracto y concreto, etc. Lo que destacamos de este procedimiento es que enlaza, a través de la explotación de las relaciones sintagmáticas del significante, diversos contenidos que, por aparecer en contigüidad, proponen la posibilidad de una semejanza semántica o, por lo menos, una hipotética congruencia entre las magnitudes discursivas articuladas.

Existe, pues, un procedimiento propio de la escritura que Leonardo Padura asume de un modo decidido y visible: la conexión entre contenidos no ligados a través de las operaciones sintácticas del significante. Para entenderla con precisión, debemos antes recordar que la lógica del significante se haya determinada por una característica que localizó Saussure: la linealidad. Por el origen fonológico del lenguaje humano, la enunciación lingüística está obligada a la sucesión de los sonidos y, por ello, a la configuración de la significación con ayuda de la 
memoria, la que recompondrá una totalidad desde lo que deviene como aspectual, es decir, de lo que aparece en una sucesión de aspectos de cariz diferente: uno inicial, otro durativo y otro terminativo. Nos interesa destacar que dicha linealidad aspectualizante propicia, en el plano de la expresión, una suerte de aplanamiento de la profundidad: una proyección de la presencia de los múltiples referidos en una continuidad no simultánea.

Este rasgo permite colocar en la misma dimensión hechos o magnitudes discursivas múltiples, diluyendo la profundidad espacial, aquella que provee al pensamiento de una gran metáfora conceptual con la cual ubicar relaciones categoriales de diversa índole. Con la escritura, esta operación se vuelve objetiva y adquiere la forma de una rejilla: la linealidad del signo lingüístico se transforma en una estructura tabular dentro de la faz formal del objeto libro o de otros soportes de inscripción ${ }^{3}$. Este aplanamiento significante de la escritura tiene como consecuencia la homogeneización probable de las magnitudes convocadas con diversos grados de presencia dentro de un discurso y su convivencia en la misma estructura.

Según Jacques Rancière, aunque con otros términos, este procedimiento es intencional por primera vez en la escritura de Flaubert. Luego de analizar un pasaje de Madame Bovary, el filósofo francés sostiene que "el novelista es plenamente consciente de lo que hace, aquí, al sumergir en un mismo régimen de indeterminación los enunciados y las percepciones" (2009, p. 149). Y añade que este es un modo antisintáctico de usar la sintaxis. Lo que esta realiza habitualmente es "distinguir lo objetivo y lo subjetivo, establecer un orden causal entre las acciones o las emociones, subordinar lo accesorio a lo principal" (p. 151). Dichos poderes de la sintaxis se ven diluidos en la escritura flaubertiana: los elementos se hallan en una sucesión que no distingue jerarquías, las acciones y sus "interrupciones" narrativas son colocadas, gracias a la linealidad, en conexión que relativiza cualquier concepción que pretenda organizar el mundo de un modo tradicional. 
A este procedimiento es al que podemos denominar como "estructuración metonímica de la realidad", la que es factible gracias a la linealidad del significante y a su objetivación que la escritura permite. Con ello, las magnitudes más diversas y dispares desde el punto de vista semántico se ven armonizadas y resultan convincentes en su sucesión. Este procedimiento tiene, en la escritura de los cuentos de Padura, momentos de gran visibilidad. Lo que creemos es que dichos pasajes sintetizan y concentran la significación que se halla en sus relatos y que, por eso, predominan y hacen visible una posición ética respecto del mundo.

\section{Continuidades enuncivo-enunciativas en "Según pasan los años"}

Observemos, sin más preámbulos, algunos casos de este procedimiento en los cuentos reunidos en el libro Aquello estaba deseando ocurrir, que también aparecen en su Antología personal. El relato "Según pasan los años”, de 1985, inicia con el encuentro de Lucrecia y Elías en el entierro de un amigo común, Juan Carlos, muchos años después de su separación. Pocos párrafos después de los primeros diálogos, el lector observa cómo uno de los protagonistas se entera de este fallecimiento en la mañana de aquel día:

Cuando Hortensia lo despertó, Elías, vamos, muchacho, aquella mañana que siguió a su regreso, y le dijo, él medio dormido todavía: mi hijo, vamos, tengo que decirte una cosa, él jamás pudo imaginar que su madre fuera a darle esa noticia. (Padura, 2015)

Como puede observarse - $\mathrm{y}$ usando una metáfora de Rancière-, en el hilo de la sintaxis, las "perlas" de los enunciados del narrador y los de la madre se enhebran sin jerarquías. Quizás solo la musicalidad de las palabras, un fenómeno de linealidad significante, haga emerger la verosimilitud del relato, la cual no se encuentra determinada por ninguna subordinación conceptual.

Esta secuencia dispone, para el lector, una convivencia armonizada entre tres magnitudes discursivas de distinta naturaleza: la presencia del narrador, los 
enunciados de un personaje y los pensamientos de otro. Poco más adelante, en el mismo relato, puede observarse hacia el interior del mundo representado una armonización entre realidades diferentes que tiene como efecto un estado de ánimo de cierta complacencia, una que contrasta con el momento fúnebre. Al final de la ceremonia, empieza a llover fuertemente y Lucrecia exclama:

-Por Dios, qué clase de día.

- Cualquiera es malo para morirse — filosofa Elías.

-Esto parece una película inglesa. No sé.

Elías la mira y no puede evitar una sonrisa. A Lucrecia siempre se le ocurren cosas así, y es cuando se le ocurre a él, viendo el desfile de autos que se retiran, que tal vez Juan Carlos estuviera vivo y todo fuera la sabida historia de hacerse el muerto para ver el mal entierro que le hicieron. (Padura, 2015)

En este caso se producen conexiones sostenidas por la linealidad metonímica entre la representación de la lluvia, el recuerdo de una película, la recuperación del ánimo de un personaje, el hecho del desfile de los autos y la posibilidad de una broma macabra. Lo que en el pasaje anteriormente citado era una conexión entre magnitudes del relato y de su enunciación, se convierte, en el que acabamos de observar, en un conjunto de nexos sucesivos dentro del mundo representado por los enunciados. No obstante, la posibilidad presentada al final de la secuencia citada, aquella en la que un personaje pudiera no haber muerto, nos reenvía de la dimensión enunciva a la enunciativa, de lo representado al acto de su representación. Y esto es así porque a continuación, con el disparador de esta posibilidad, el relato despliega una serie de superposiciones de tiempos a través de la intercalación de diálogos entre Lucrecia y Elías ocurridos en dos periodos diferentes de sus vidas.

Muchos años antes de la muerte de Juan Carlos, cuando todos ellos eran jóvenes, Elías la había invitado a una fiesta con un grupo musical que en realidad no se realizaría; su verdadera intención era tener la oportunidad de un encuentro nocturno y a solas con Lucrecia. En un momento, hacia el final del cuento, el narrador le da la palabra a su personaje femenino: 
Me miraste con una cara que de verdad yo pensé que había pasado algo malo.

- Oye, Lucrecia, tengo que darte una mala noticia - dijo-. Me dijeron ahorita que Ringo, el baterista de los Kent, está enfermo y suspendieron la fiesta.

- ¿Y adónde vamos por aquí? - preguntó y observó el movimiento difícil de la nuez de Elías. Tragaba en seco y disimulaba encendiendo un cigarro.

— Mas nunca he entrado aquí, Elías — dice ella—. ¿Cuántas veces vinimos juntos?

— ¿Te acuerdas del día que no nos alcanzó el dinero?

— Fue la última vez que vinimos. Ya llevábamos como quince meses de novios. Quince meses, mi madre. (Padura, 2015)

Como dijimos, son dos momentos vividos por los mismos personajes en los mismos lugares, aunque en tiempos diferentes, y que se intercalan amparados por la linealidad del significante y preparados por los movimientos antes descritos, aquellos en los que quedan enlazadas realidades distantes en el enunciado y también de distintos niveles de pertinencia semiótica: la narración y lo narrado. De este modo, se produce una verosímil continuación entre los hechos y los actos discursivos que lo toman a su cargo: la materia con la que se puede construir el sentido, la materia significante, y los hechos que no tienen en sí mismos significación se enlazan, por medio de estas operaciones, de modo solidario.

Esta continuidad llega a ser embriagante, no solo por todo el ron que en el encuentro han bebido los personajes, sino también por la continuidad alucinada de los lazos metonímicos. Hacia el final del relato, los personajes experimentan a través de la música un cortocircuito temporal:

¡Coño?, dicen a dúo, ahora pasa lenta y distraídamente una canción de Los Beatles, qué es esto, "Fool on the Hill", y ¿en qué año estamos? ¿Será verdad que estuve dos años en la guerra de Angola o esta misma tarde estaba jugando pelota en el patio del Pre? (Padura, 2015)

De este modo, la concentración que podemos llamar "aléphica" — aludiendo a un conocido cuento de Borges - de los tiempos, los lugares y los discursos acentúa y justifica la textura del relato y su modo de manejar las realidades disociadas con 
las que los personajes quieren armonizar sin lograrlo en el universo representado, en la dimensión enunciva, pero que sí se logra en el plano de la enunciación: los personajes, al final, se separan, cada quien se va a su casa y las líneas de continuidad de sus vidas se bifurcan. No obstante, en el discurso conviven tensa pero consistentemente diversos tiempos, escenarios y personajes.

\section{La marginalización solidaria del lector en "El cazador"}

En otro cuento muy celebrado, llamado "El cazador" y de 1990, también podemos observar procedimientos de configuración metonímica semejantes. A través de la forma del relato lo que se expone es, antes bien, una manera de existencia en la marginalidad. Las transformaciones narrativas son un procedimiento funcional para la exposición de la situación del homosexual en La Habana, un entorno que no consciente con ese estilo de vida o condición de ser y lo obliga a desplegar su sexualidad en el reverso sórdido, secreto y nocturno de la sociedad. En tal sentido, resulta paradójico el título del cuento que, antes bien, delinea un sujeto atrapado, encorsetado, detenido y sin visos de algún tipo de liberación.

El procedimiento de la conexión metonímica y significante entre magnitudes semánticas dispares también juega un papel en este cuento. En un momento de la noche por medio de la cual conocemos el modo de vida del personaje, este logra ubicar a una posible presa, un joven estudiante que espera, cerca de la media noche, para entrar al cine. La conversación fluye: los estudios de idiomas, la carrera y el protagonista se imagina una escena íntima, luego de lo cual el narrador expone en indirecto libre - estilo con el que se organiza todo el cuento- el deseo de su personaje bajo la forma de la pregunta:

¿Aquel muchacho con aquellos ojos verdes y esa timidez visible lo besaría, lo acariciaría, lo abrazaría casi hasta asfixiarlo y finalmente lo montaría, haciéndolo gozar la dureza ajena clavada en las entrañas?

«Disculpa», dijo entonces el joven, «pero tengo que llamar por teléfono. Mi esposa debía estar aquí a las diez». «No te preocupes», dijo, y casi sintió deseos de golpearlo. (Padura, 2015) 
En este caso, la reflexión del narrador en el estilo indirecto se interrumpe con la voz del otro personaje en estilo directo y, repentinamente, la apetecida presa se le escapa. En su lugar, deviene la furia. El diálogo, la fantasía, el iracundo descontento se conectan contrastante, vertiginosamente y empalman sus sentidos ante los ojos del lector que no percibe desencuentros semánticos sino un flujo metonímico armonizado por la lógica del significante. Otro pasaje semejante es aquel en el que, hacia el final de la noche, logra encontrar una presa, aunque menos apetecible mucho más segura:

Tampoco podía seguir solo, cazando sin fortuna cada noche, oliendo a masturbaciones y a saliva, esperando el milagro del amor. Necesitaba entregarse, o que se le entregaran.

— Oye, hazme el favor, mi niño — le dijo.

Cerró la puerta y pasó los pestillos. Sobre el sofá de la sala dejó la camisa y se quitó los zapatos sin desatar los cordones. Fue hasta el baño y antes de lavarse las manos adoloridas, se miró en el espejo. Sus ojeras de siempre habían crecido, eran dos bulbos oscuros a punto de desprenderse. (Padura, 2015)

Toda la escena del encuentro homosexual es suprimida: se encuentra en el hipotético tiempo de la historia, pero desaparece en el tiempo del relato. Lo que se presenta al lector es la continuidad exclusivamente significante entre el inicio de un diálogo y la soledad física y anímica del personaje en el espacio privado. En este caso, se hace evidente que la articulación meramente significante de los sucesos narrativos tiene por función poner en evidencia el carácter disruptivo y marginal de la subjetividad del personaje acompañado desde muy cerca, pero también mostrarlo como un heterogéneo interior. La escena sustraída es luego retomada por retazos que no impiden, sino que provocan la viva implicación del lector y su imaginación.

Se trata entonces de incorporar al enunciatario en la escena del personaje marginal, se trata de que lo perciba como este no puede: atrapado, encarcelado, pese a que él se imagina como cazador voraz. El recurso de la estructuración metonímica de la realidad tiene en este caso la función de permitir, desde el plano 
de la expresión, el pensamiento de una inscripción, aquella del sujeto marginal como parte de su comunidad, aunque no desde la configuración paradigmática de la misma, es decir, no a través de un conjunto de rasgos distintivos que lo inscriban. Lo que con este procedimiento se logra tradicionalmente es la exclusión de identidades

de este tipo: pensar, por ejemplo, al cubano de esta manera — es decir, a través de ciertas "esencias", tales como el lugar de nacimiento, el dialecto, las tradiciones, la habitación en la isla, etc. - no permite inscribir fácilmente al homosexual protagonista del relato dentro de la categoría a la que, sin embargo, pertenece: él es un cubano. Por el contrario, la supresión de la escena y el consecuente compromiso del lector en la elucubración de lo sustraído implican la inclusión de este sujeto marginal en la comunidad, inclusión que se halla determinada por el interés que podría sentir el lector por el personaje y por su devenir.

\section{La poética metonímica de Padura en "La puerta de Alcalá"}

"La puerta de Alcalá" de 1991 es quizás el cuento que mejor permite observar, en su construcción, la estructura que denominamos metonímica de la realidad. El mismo inicio es la articulación entre dos enunciados contrastantes y dispares:

Siempre había oído decir que llamar a las desgracias acaba por traerlas. Y el Jornal de Angola anunciaba otra vez una inminente invasión sudafricana. (Padura, 2015)

Son dos oraciones que se enlazan por la sucesión sintagmática y vinculan un saber anónimo, expresado en una sentencia popular e incontrastable, y un enunciado que se conecta con hechos relativos a la experiencia personal del narrador, la de ser periodista enviado desde Cuba a zonas de conflicto en el continente africano. El personaje focalizado es también un periodista y el narrador inicia su historia con el temor y las consecuencias fisiológicas que este afecto le causan:

Sólo que aquel miedo sí podía tener efectos inmediatos. Apenas había leído el titular y unas líneas del primer párrafo y debió abandonar la cama y andar deprisa hacia el baño, con el periódico bajo el brazo, mientras desabotonaba su pantalón. (Padura, 2015) 
Como se puede apreciar, la conexión entre la lectura del periódico y los efectos en el sistema digestivo resultan verosímiles, la metonimia es aquí inscrita dentro de la relación entre una causa informativa y un efecto fisiológico. Sin embargo, esta articulación se complementa con otra: un gesto más gratuito y menos lógico:

Por eso, sentado en la taza, se dedicó a rasgar con esmero la parte de la primera plana que desataba sus angustias, dispuesto a vengarse del modo más escatológico y simbólico que conocía: se limpiaría el culo con la noticia. (Padura, 2015)

Las relaciones inopinadas entre la información y el cuerpo, entre los significantes y los hechos adquiere un cariz no convencionalmente referencial. De todos modos, la asociación resulta verosímil y, aunque de modo más singular, también es representativa. Estos nexos de naturaleza cómica, de nivel enuncivo y propios del mundo representado, solo anuncian los enlazamientos dispares más complejos que luego se presentarán con la instancia a cargo de la significación, con la enunciación narrativa.

A partir de una serie de conexiones azarosas, el relato logra hacer verosímil, no obstante, la estrecha relación entre un cuadro de Velázquez, las notas dejadas por una mujer en un libro, un viaje a España, el encuentro con un amigo, la memoria de la juventud y sus posibilidades, y, lo que resulta más importante, una suerte de poética sobre la articulación metonímica de los significantes para la construcción verosímil de la realidad. Efectivamente, cabe afirmar que el cuento alberga, una serie de datos que permiten entender una definición de la literatura propia del narrador. Uno de ellos que destacaremos se presenta encubierto como una cita de Proust, un enunciado cuya función no es fundamental en el avance de la historia, pero aloja un detalle, una pista del procedimiento narrativo.

En la segunda parte del cuento, los dos amigos cubanos se encuentran insospechadamente y conversan entre tazas de café, cigarrillos, copas y platos de comida en un restaurante de Madrid. Uno de ellos, el que era arquitecto y amigo de la universidad del periodista, le dice a este: 
- [...] Mira, hace como tres años, leyéndome a Proust me acordaba de ti, ¿te acuerdas que tú fuiste el único en el pre que se leyó Un amor de Swann? Y hay una parte, creo que en $A$ la sombra de las muchachas en flor, en que el cabrón dice que, más o menos así, une más la consanguinidad de espíritu que la identidad de pensamiento...

-Proust tenía serios problemas ideológicos. En mi periódico no duraba una semana... (Padura, 2015)

Dicha sentencia, aquella según la cual "une más la consanguinidad de espíritu que la identidad de pensamiento..." puede pasar desapercibida como una que, apelando a la erudición, expresa de modo sesgado la amistad de dos cubanos reencontrados y la nostalgia por los tiempos universitarios, aquellos de las posibilidades abiertas. No obstante, esta frase ubica también, de modo velado una relación, flaubertiana, entre lo sensible y la verdad. Esta observación es igualmente de Rancière, a quien ya citáramos poco más arriba. El filósofo francés nos recuerda una sentencia un poco críptica de su compatriota escritor hallada en una carta dirigida a mademoiselle Leroyer: "Cuanto más bella es una idea, más sonora es la frase" (cfr. Rancière, 2009, p. 152). De este modo, comenta Rancière, el capricho de Flaubert exige "a la sonoridad de la frase que pruebe la verdad de la idea" (Rancière, 2009, p. 152).

En el caso del enunciado atribuido a Proust, lo que reemplaza la razón es una filiación espiritual, una hermandad que suprime toda diferencia que la lógica no logra resolver. En cambio, el capricho estético de Flaubert afirma que es la musicalidad lo que sustituye a la razón y prueba la verdad de una sentencia. En todo caso, ambos enunciados contienen alternativas al imperio de la razón y del pensamiento. No son estos y las jerarquías que imponen las que permiten conocer ordenadamente el mundo, sino que el mundo obedecería a otro orden, uno superior detrás del orden falso e impuesto por la racionalidad instrumental y moderna. Para acceder a él, deberíamos suspender las jerarquías, las categorizaciones, las correspondencias semánticas y conectar inopinada, azarosamente, por medio del hilván metonímico y significante las diversas porciones de la realidad, aunque no 
se condigan en el mismo nivel de pertinencia semiótico y dejar entrever, así, una nueva organización convincente de la realidad.

En otro pasaje de "La puerta de Alcalá", ubicado en la primera parte, se describe una pintura de Velázquez que será un motivo recurrente: una expresión de la felicidad de un creador que logra un dorado equilibrio entre las exigencias del poderoso y la creatividad:

Aquella tarde magnífica en el jardín de los Médicis daba deseos de vivir y trasmitía el júbilo que debió sentir el artista mientras dejaba correr, libre y sin compromisos con reyes más o menos comprensivos y generosos, sus mejores pinceladas de hombre apacible. (Padura, 2015)

En la segunda parte, otro cuadro del mismo pintor es también motivo de elucubraciones metonímicas:

Entonces observaba otra vez La Venus del espejo y admiraba la valentía de Velázquez, y su sentido de la libertad artística que ningún rey le pudo arrebatar del todo. (Padura, 2015)

Es tentador pensar, relacionando estos dos pasajes, en una alegoría de la posición enunciativa de un narrador en una circunstancia como la del propio Padura: alguien que debe vivir a la sombra directa de un poder estatal y que, no obstante, es capaz de no sucumbir bajo ese poder por una genialidad artística que le permite trascender... En todo caso, es significativo que a continuación, en oración seguida, las continuidades inopinadas se desplieguen de inmediato:

¿Quién fuiste, quién eres en realidad, María Fernanda?, se preguntaba tratando de robarle a la penumbra del espejo el rostro creado por el pintor, y soñaba. (Padura, 2015)

Aquí se produce un desdibujamiento de límites entre lo propio de cada una de las presencias articuladas: el rostro de la Venus es tomado para darle forma a un personaje de la ensoñación de otro, uno que nunca conoció el personaje focalizado o que solo conoció a partir de los apuntes dejados en las márgenes de un libro sobre el pintor español. Hay en esta continuidad entre la posible 
representación alegórica de la posición enunciativa y la confusión entre los límites de las presencias reunidas (efecto de una operación metonímica) una relación que podemos leer como el indicio de una comunión.

Se trataría del intento, renovado siempre, de imponer una visión estética del mundo allí donde no siempre es probable o factible realizarla con el instrumento de la escritura, aquel que permite conectar, con la verosimilitud de la sintaxis, realidades distantes con el propósito de pensar un nuevo modo de construcción de totalidades.

Así, pues, puede entreverse una poética, aquella que se hace explícita en los términos de una definición esencial, propia de Leonardo Padura y respecto de la literatura narrativa: esta sería la representación de la realidad que se realiza por medio de un procedimiento específico y de naturaleza significante, aquel de la conexión entre magnitudes discursivas múltiples, sin relación semántica visible — por lo menos esto sería así desde la perspectiva de las fuentes de sentido institucional o tradicional—, cuyo único soporte de verosimilitud es la continuidad metonímica de los significantes. Gracias a la escritura, esa continuidad verosímil que no empata con el sentido común puede quedar fija y repensarse como una posibilidad más allá de las formas canónicas de pensamiento.

\section{Para concluir y conectar}

De este modo resulta visible que, para Leonardo Padura, en los cuentos que hemos revisado, la escritura implica una relación muy sólida entre procedimientos de escritura y compromisos éticos. En síntesis, podríamos concluir lo siguiente:

1. En la posición enunciativa resulta destacable el deseo de intervenir en la realidad y crear totalidades abiertas cuya significación no se sostenga en las fuentes institucionales de sentido. Estas nuevas significaciones integradoras permitirían incorporar el sentido construido en la significación narrativa a la realidad y transferir la realidad al sentido construido en el relato.

2. Dichas totalidades no jerárquicas ni institucionales que producen integraciones entre la ficción y la realidad se sostienen en un procedimiento retórico 
particular de la prosa, aquella que hemos denominado como "estructuración metonímica de la realidad", y que consiste en un "aplanamiento" de la profundidad y la diversidad semánticas a través de la articulación sintáctica propia de la escritura: por medio de la redacción lineal de la prosa, la diversidad contrastante o simplemente múltiple referida o significada cohabita armonizada ante los ojos del lector.

3. En el cuento "Según pasan los años", los más diversos saltos en el tiempo y en el espacio, propios de los enunciados en los que se construye la realidad representada, se continúan y armonizan en la instancia de la enunciación. El resultado es una tensión entre el desencuentro referido e imaginado por el relato, por un lado, y la conciliación y armonización, por el otro, que la escritura permite y que se hallan inscritas en la instancia de la enunciación.

4. En "El cazador", la prolijidad descriptiva contrasta con ciertas conexiones entre dos momentos de un sórdido recorrido nocturno de un homosexual que deja un vacío para la imaginación. Gracias a él, el lector resulta implicado directamente como el agente de la reconstrucción de lo no relatado. De este modo, la representación de un sujeto marginal logra una inscripción dentro del mismo espacio social junto con el lector. Ello es así debido a que el interés que suscita lo no contado puede entenderse como un modo de lazo solidario con aquel que, de otro modo, no sería fácilmente aceptado en su sociedad.

5. Finalmente, en "La puerta de Alcalá" se pronuncia en voz baja una poética de la escritura narrativa de raigambre flaubertiana. En ella, se propone una suspensión de jerarquías y correspondencias semánticas de sentido común para, en su lugar, hilar metonímicamente, por medio de la prosa narrativa, diversas zonas de la realidad que no embonan habitualmente, pero que terminan armonizadas por la escritura, dejando así implícita la posibilidad nuevos órdenes de organización de la realidad.

En suma, cabe la sospecha de que los cuentos de Padura son ensayos narrativos para estas operaciones que se desplegarían más intensa y extensamente 
en sus novelas. Algunos críticos consultados podrían coincidir con esta hipótesis ${ }^{4}$. Pero su constatación es una promesa para ensayos posteriores, el que queríamos presentar, en esta ocasión solemne, termina justo aquí.

\section{Notas}

1 En este punto nos orientamos por la enseñanza de Jacques Lacan quien, en el Seminario 18, llamado De un discurso que no fuera del semblante, propone que lo escrito es el resultado sedimentario de las repeticiones de la palabra. Así, pese a que es segundo respecto de la función del lenguaje, sin lo escrito no se puede revisar e incluso cuestionar lo simbólico como efecto de la mencionada función (cfr. 2009, p. 59). Sin él, no se puede interrogar el lugar del Otro de la verdad, porque "solo por lo escrito se constituye la lógica" (p. 60).

$2 \mathrm{Al}$ respecto pueden leerse, entre otras, las indagaciones sobre las novelas de Leonardo Padura que han sido consultadas y aparecen en la bibliografía: "Márgenes de la ciudad como márgenes de la nación en la cola de la serpiente de Leonardo Padura" de Karla Aguilar; "La escritura como marca y máscara del significante ausente: Leonardo Padura y la visible ausencia de Guillermo Cabrera Infante" de Claudia Hammerschmidt y "Leonardo Padura Fuentes: las máscaras estéticas y sexuales de la Revolución” de Óscar E. Montoya. En estos trabajos, sus autores pretenden demostrar la correlación compleja entre la realidad histórica, las filiaciones estéticas del autor cubano y sus relatos de ficción. Lo que aquí proponemos es que esas articulaciones semánticas y referenciales tienen un muy específico procedimiento retórico y significante.

3 La diferencia entre faz formal y faz substancial ha sido establecida por Jacques Fontanille en Prácticas semióticas (2014). Para este caso, la faz formal del libro como objeto es su superficie de inscripción, aquella que acoge el texto. Por su parte, la faz substancial del mismo es aquella que le permite interactuar con el lector en el proceso de la lectura: su resistencia, su durabilidad, su ductilidad, su peso, etc.

4 Algunos, como Karla Aguilar, han sostenido que una de las inquietudes de la narrativa de Padura es el pensamiento de la nación; pero no a la manera de la delimitación constituida por rasgos para la configuración de un conjunto, una salida paradigmática, sino a través de la historización. Narrar es para Padura historizar en el sentido de que con el relato resulta verosímil una reflexión de lo propio a través de la incorporación de lo otro: una salida sintagmática. La 
narración no sería un fenómeno esquemático para el despliegue de categorías fundamentales, sino, antes bien, un modo de suspender la categorización y, así, permitirse pensar en lo otro en una relación no conceptualizada con lo propio. Es probable, como venimos diciendo en este ensayo, que este deseo resulte visible en una de las operaciones retóricas de la escritura de Padura: la continuidad metonímica entre magnitudes discursivas de diversa índole: hechos orgánicos con acontecimientos históricos, recuerdos con sensaciones, con olores y conceptos.

\section{Referencias bibliográficas}

Aguilar, K. (2016). Márgenes de la ciudad como márgenes de la nación en la cola de la serpiente de Leonardo Padura. Perifrasis. Revista de Literatura, Teoría y Crítica, 7(14), 52-63. Recuperado de: http://dx.doi. org/10.25025/perifrasis201671404

Fontanille, J. (2014). Prácticas semióticas. Traducción de Desiderio Blanco. Lima: Universidad de Lima Fondo Editorial.

Hammerschmidt, C. (2014). La escritura como marca y máscara del significante ausente: Leonardo Padura y la visible ausencia de Guillermo Cabrera Infante. Hispanic Revie, 82(3), 359-376. doi: 10.1353/hir.2014.0027

Lacan, J. (2009). De un discurso que no fuera del semblante. Buenos Aires: Paidós.

Márchese, Á. \& Forrandellas, J. (1988). Diccionario de retórica, crítica y terminología literaria. Barcelona: Ariel.

Montoya, Ó. E. (2012). Leonardo Padura Fuentes: las máscaras estéticas y sexuales de la Revolución. Hispanic Review, 80(1), 107-125.

Ranciere, J. (2009). La palabra muda. Ensayo sobre las contradicciones de la literatura. Buenos Aires: Eterna Cadencia.

Padura, L. (2015). Antología personal. San Juan de Puerto Rico: Editorial Universidad de Puerto Rico. 